\title{
SOME RESULTS OF FORAGE FISH INVESTIGATIONS IN MICHIGAN
}

\author{
Gerald P. Cooper
}

\begin{abstract}
Institute for Fisheries Research, Michigan Department of Conservation, and University of Michigan
\end{abstract}

Some of the results of the forage fish investigations, conducted by the writer during the past two years for the Institute for Fisheries Research of the Michigan Department of Conservation, constitute the subject matter of this paper. The investigations have included: (1) the experimental propagation of certain forage species in ponds, (2) observations on the life histories of certain species in natural waters and in hatchery and other rearing ponds, and (3) experiments at the Institute Laboratory in the Museum of Zoology of the University of Michigan.

\section{Propagation Experiments}

During 1934 the writer cooperated with the late Henry A. Schuil in conducting certain propagation experiments on six species of forage fishes at "Schuil Acres," an experimental rearing station which he had constructed at Grand Rapids, and which at this time was operated under the Department of Conservation. During 1935 the following experiments were conducted: the propagation of the western golden shiner (Notenigonus crysoleucas auratus) and the chub sucker (Erimyzon sucetta kennerlii) in two trout-rearing ponds, owned by U. Sidney Beach, at Highland, Oakland County, Michigan; propagation of the northern red-bellied dace (Chrosomus eos) in a single pond at the Drayton Plains state fish hatchery; and propagation of the bluntnosed-minnow (Hyborhynchus notatus) and the northern fat-head minnow (Pimephales promelas promelas) in a single pond at Utica, Macomb County, Michigan. Although complete results are not yet available on all of the 1935 experiments, sufficient information has been obtained to justify mentioning these experiments.

\section{"Schuil Acrfs," 1934}

The Schuil station consisted of a series of 5 artificial ponds, situated along the banks of a small stream. During the early spring the empty pond basins were fertilized, with a total of 7,200 pounds of cow manure and 300 pounds of sheep manure (total cost, $\$ 26.70$ ). The water supply for the ponds consisted of seepage from the adjacent stream and from underground springs. The different amount of spring seepage into the ponds was reflected in the wide difference in water temperatures of the ponds during the summer (Table 1).

Various physical data on the ponds, taken during the course of the experiments, are summarized in Table 1 and Figure 1. All ponds 


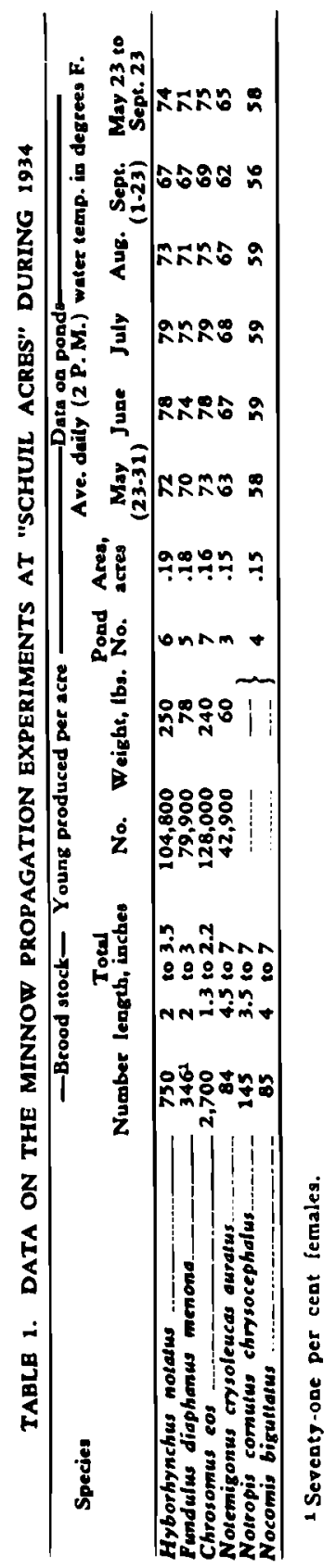




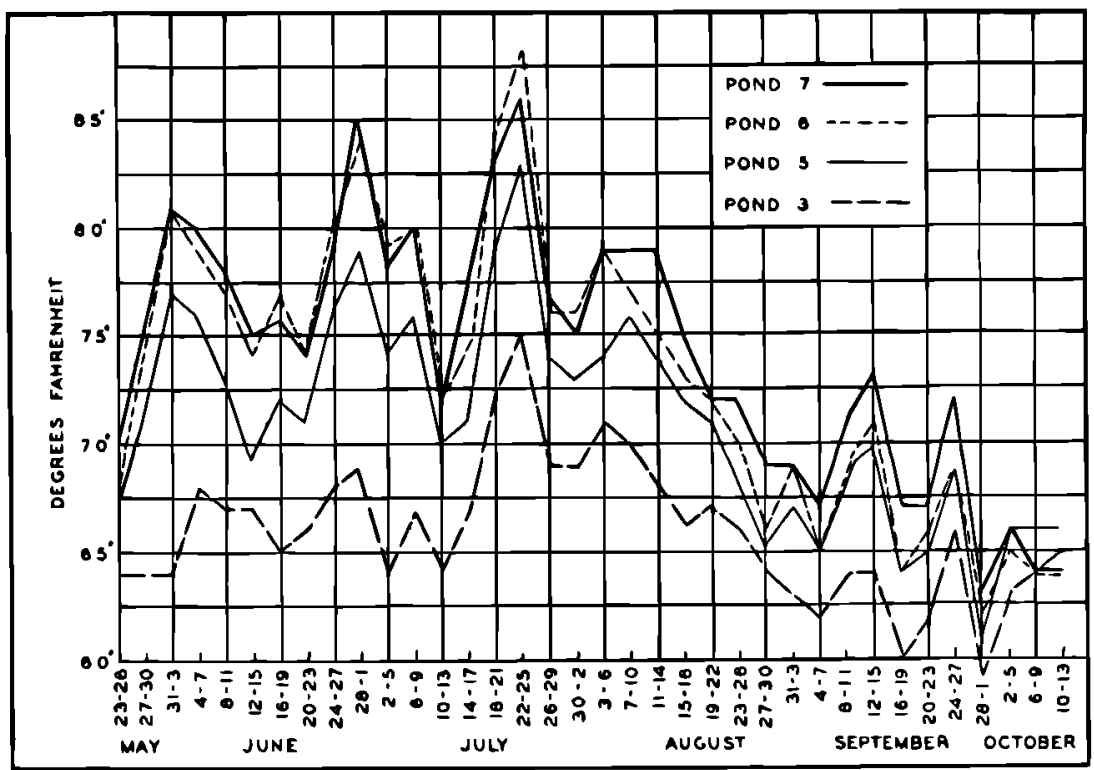

Fig. 1-Graphs showing average water temperatures in ponds at "Schuil Acres" during 1934. Each temperature plotted above is an average of 4 consecutive readings taken daily at 2 P.M. Detailed data not given in this paper.

maintained an abundant growth of Chara, and ponds 5, 6 and 7 also supported a considerable growth of filamentous algae.

Six species were used for the propagation experiments in the five ponds, namely: the blunt-nosed minnow (Hyborhynchus notatus) in pond 6 , the Menona killifish (Fundulus diaphanus menona) in pond 5 , the northern red-bellied dace (Chrosomus eos) in pond 7, the western golden shiner (Notemigonus crysoleucas auratus) in pond 3 , and both the common shiner (Notropis cornutus chrysocephalus) and the hornyheaded chub (Nocomis biguttatus) in pond 4. The common shiner and the horny-headed chub were used together in the one pond as an attempt to take advantage of the symbiotic spawning relationship which occurs naturally, in some localities, between these two species (Hankinson, 1932). Various spawning devices were installed in the pond used for the blunt-nosed minnows. The number and size range of the breeders put in each pond during the spring are indicated in Table 1.

Throughout the summer the fish population of each pond was fed daily, using cooked cornmeal and oatmeal (275 pounds) mixed with bone meal (200 pounds) and clam meal (400 pounds). The 875 pounds of feed used during the entire summer represented a cost of 
TABLE 2. SIZE FREQUENCIES OF YOUNG "MINNOWS" IN THB RANDOM SAMPLES OBTAINED FROM THE "SCHUIL ACRE" BXPERIMENTS

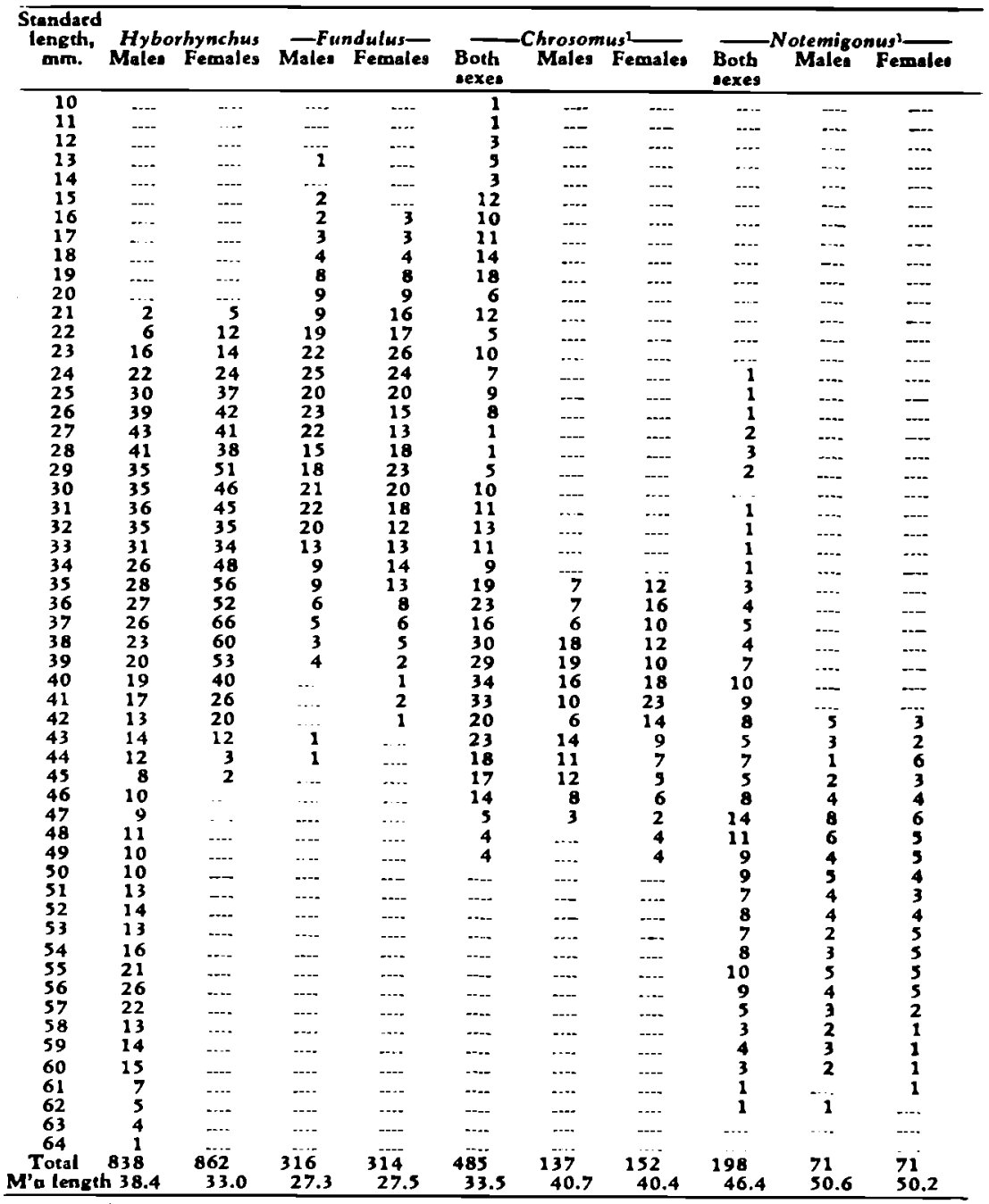

1 The data for the two sexes are combined in the graph, since accurate sex determinations were impossible on the smaller specimens, and since there is no sex difference in length in the larger specimens.

$\$ 34.75$. The cost of fertilizer and feed for the entire experiment was approximately $\$ 12.00$ per pond.

The common shiners and the horny-headed chubs in pond 4 produced no young; throughout the entire summer there were no indications of attempted spawning. But since the water in pond 4 was 


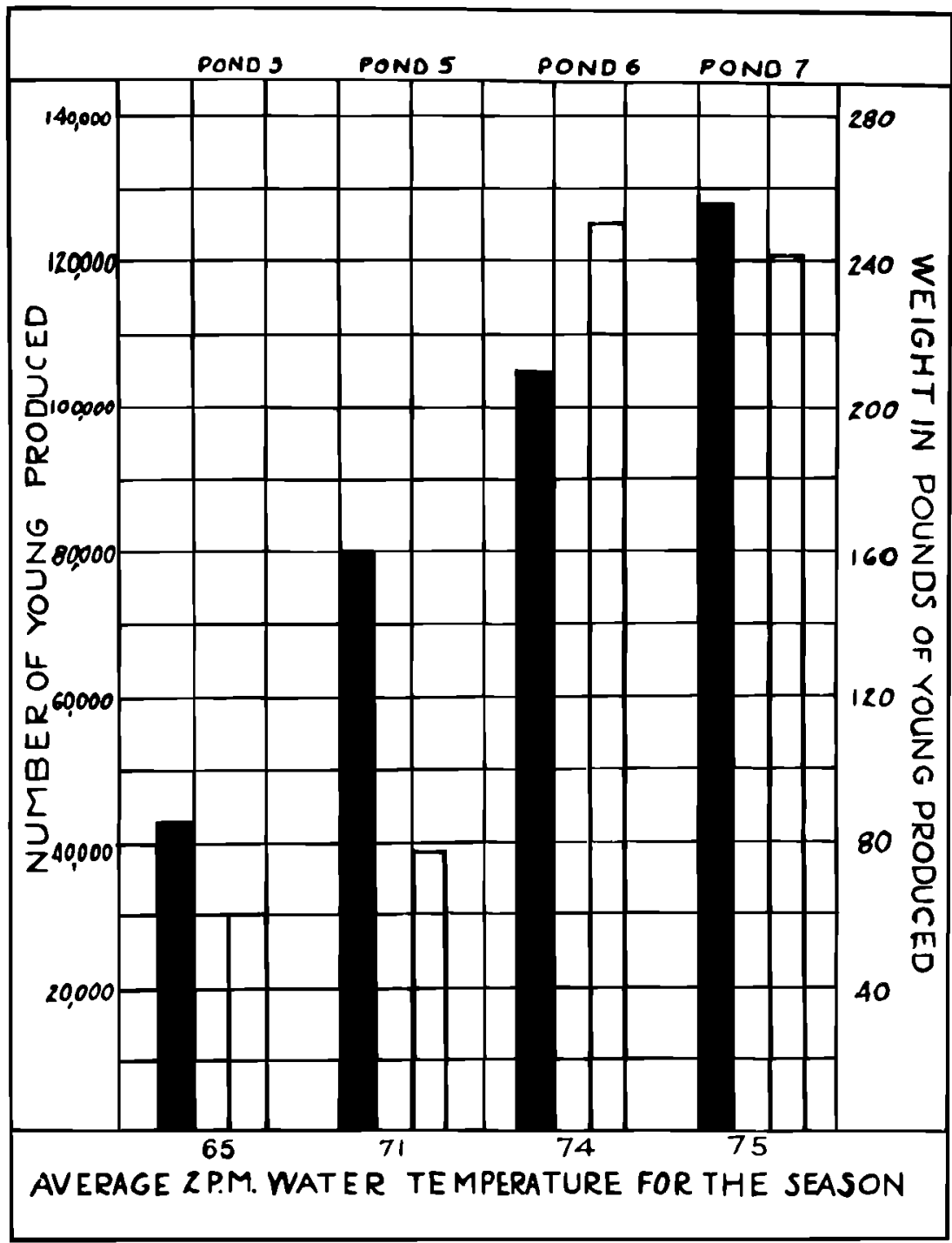

Fig. 2-Productions per acre of forage fishes, obtained at "Schuil Acres" during 1934, given in numbers (solid rectangles) and weight (open rectangles). The species involved are: the western golden shiner in pond 3 , the Menona killifish in pond 5 , the blunt-nosed minnow in pond 6 , and the northern red-bellied dace in pond 7. Data from Table 1. 
probably too cold (attaining a maximum of slightly over 60 degrees $\mathrm{F}$. for only a few days during the entire summer) to permit spawning by these two species, this evidence is not sufficient to prove that these naturally stream-spawning species will not reproduce in ponds. The other 4 species were successfully propagated (data given in Table 1 and Figure 2). The ponds were drained late in the fall and a random sample from the total population of each pond was preserved for study.

The length-frequency distributions of the young minnows in these random samples are given in Table 2 and Figures 3, 4, 5 and 6 . The bimodality of the length-frequency curves of the young Hyborhynchus (Fig. 3), Fundulus (Fig. 4), and Chrosomus (Fig. 5) produced in

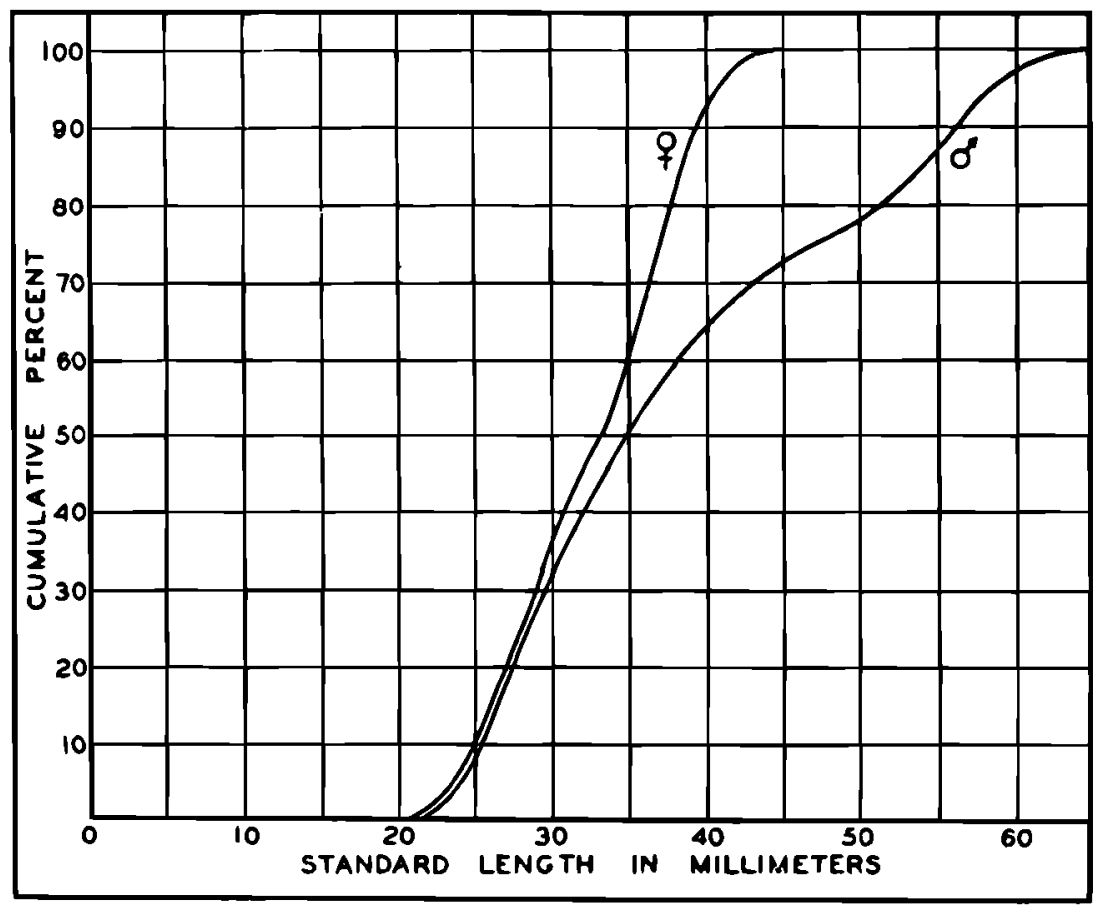

Fig. 3-Showing that the more rapid rate of growth of the males of the bluntnosed minnow is first definitely manifest at a standard length of 30 to $35 \mathrm{~mm}$. From data given in Table 2 on the length frequencies of each sex of young in the random samples taken from the Schuil Pond. These curves were constructed by plotting the per cent of the total sample of each sex which was smaller than, and included by, each millimeter of standard length. The assumption is made that the sex ratio among the young produced at various times during the season was constant. 
ponds 6,5 , and 7 , respectively, presumably resulted from a common cause. The most obvious explanation for this apparently abnornal bimodal size distribution is that the main spawning season of these three species, known to have occurred from the middle of June through July, was retarded considerably during the second week of July by low water temperatures (Figure 1). This bimodality is so marked in Figures 3 and 5 as to erroneously suggest two-year classes.

The wide differences in production (both in numbers and in weight) obtained with these 4 species in the 4 ponds was certainly due more to dissimilar environmental conditions in the ponds than to inherent differences in the potential productivity of the species used. The golden shiner, propagated in the coldest of the 4 ponds, gave the poorest production of the 4 species, yet in 1933 this species was propagated in a presumably warmer pond at the Schuil station at the rate of 235,000 per acre, and at a comparable rate in the warmer ponds of the U. S. Bureau of Fisheries station at Fairport, Iowa (Wiebe, 1935). The production per acre for the 4 ponds was closely correlated with the average water temperature for the season (Fig. 2), and with the relative abundance of aquatic invertebrates (shrimp, may-fly nymphs, chironomids, gastropods, etc.). The productions obtained with the red-bellied dace and the Menona killifish indicate that these species might well be added to the list of forage fishes suitable for pond propagation. It is believed that even better productions, than indicated here, can be obtained with these two species.

\section{Other Propagation Experiments}

The two spring-fed ponds ( 3 and 5 acres) at Highland are operated by $\mathrm{Mr}$. Beach for rearing trout and propagating bait minnows. A considerable extent of warm-water shallows with abundant aquatic vegetation (Potomogeton, Chara, algae, etc.) in each pond provides suitable habitat for the minnows. In addition to the game fish, each pond received brood stocks of golden shiners and chub suckers (Erimyzon sucetta kennerlii) during the spring of 1935 . Although data on the actual production of shiners and suckers in the two ponds are not yet available, it can be stated that both ponds will yield large productions of golden shiners, but relatively very poor productions of chub suckers in spite of an abundant reproduction. Mr. Schuil has had a similar experience in propagating this sucker in one of the ponds at "Schuil Acres," obtaining relatively few fish, which attained a large size during the first year.

During 1935, propagation of the northern red-bellied dace (Chrosomus eos) was attempted in a 0.2 acre pond at the Drayton Plains hatchery. The lack of a water supply for the pond, and the abundance of aquatic plants (Chara, Potomogeton, and filamentous and colonial gelatinous algae) resulted in virtual stagnation of the pond water, which maintained a slightly milky appearance throughout the summer. Spawn- 
ing of the dace was observed, and eggs were found, only in a very limited part of the pond where a slight seepage of fresh water entered the pond. Water temperatures ranging from 79 degrees to 91 degrees $F$. were recorded during the summer. The production from this experiment was negligible. Comparing this experiment with the successful propagation of the dace in the Scliuil pond, the writer is certain that the failure of the dace to reproduce in the Drayton Plains pond was due to water stagnation, and that either relatively cool or running water is necessary for the propagation of this northern, cold-water species.

A quite barren pond with an area of 0.25 acre, located in an abandoned gravel pit at Utica, was stocked with both blunt-nosed and fatheaded minnows during June, 1935 . The experiment is of interest in that it demonstrates what production can be expected in a pond of very low fertility. During the season the pond produced, per acre, an estimate of approximately 100,000 very small fish weighing less than 50 pounds (a fairly good production in numbers but a poor production in weight). By August 25, only a few of the young of each species had attained a total length of 1.5 inches. At the prevailing rate of growth, few specimens would have reached maturity before their third summer of life.

\section{Life History Observation Bearing on the Culture of Certain Forage Fishes}

The following life history observations are mentioned because of their bearing on the culture of certain forage fishes. Since these observations have been made entirely on fish in Michigan waters, chiefly in the southern part of the Lower Peninsula, they may not apply in all respects, such as rate of growth, age of reaching maturity, and length of spawning season, to areas with different climatic conditions.

Blunt-nosed minnow-The habit of the blunt-nosed minnow of placing its eggs on the underside of submerged objects is well known to most fish culturists. It has been pointed out by Hankinson (1919), Hubbs (1934), and others, that objects of very diverse character are utilized. The objects, observed by the writer to contain blunt-nosed minnow nests, include boards, logs, railroad ties, rocks, boulders, bricks, pieces of crock and tile, tin cans, pieces of sheet metal such as automobile paneling, strips of bark, tree limbs and pieces of tar paper.

The blunt-nosed minnow prefers, for its nest, a flat object lying directly upon the bottom, under which the male excavates a cavity. The mud-bottomed shoals are entirely avoided by the spawning fish; the sand-bottomed shoals are definitely preferred. Nests have also been found on marl-bottomed lake shoals. Water depths of less than three feet are preferred, but the species will spawn in water as deep as eight feet if spawning facilities in shallow water are inadequate.

A single female lays from 200 to 500 eggs at one time and probably spawns 2 or more times during a single season. Actual counts have in- 
dicated that the male guards nests which contain, on the average, approximately 2,400 eggs, contributed by several females. New eggs are continually added to a nest as the advanced eggs hatch. How long one of the polygamous males maintains a nest has not been determined. The spawning season extends from the latter part of May through August. The incubation period was noted as 8 to 9 days at an average water temperature of 82 degrees $F$. and 13 to 15 days at an average water temperature of 75 degrees $F$. Most attempts to hatch the eggs in aerated jars and aquaria have thus far been unsuccessful.

Among blunt-nosed minnow poptlations, there is a wide variation in size of fishes at the end of the first summer of life, due chiefly to the very long spawning season. Among the young reared at "Schuil Acres" during 1934 (Table 2), the greater rate of growth of the males over the females (a phenomenon first recorded by Van Cleave and Markus, 1929) was first manifest at a standard length of 30 to 35 millimeters (Figure 3).

The larger young of both sexes spawn early in their second summer of life; many of the smaller young spawn late in their second year, but it is doubtful if some of the males and females reach maturity before their third summer. The range in standard length of females with ripe eggs was found to be 40 to $65 \mathrm{~mm}$. and that of breeding males was found to be 56 to $84 \mathrm{~mm}$. Some fish of each sex live through four summers. These determinations, which will be treated at greater length in a later paper, do not agree well with those of Van Cleave and Markus.

Golden shiner-The spawning season of this species extends through June, July and the first part of August. The first spawning noted at the Schuil pond in 1934 was on June 6 at a water temperature of 69 degrees $F$. In the Beach ponds, the eggs $(1 \mathrm{~mm}$. in diameter $)$ were found to be abundant in masses of filamentous algae, while none were found on the various types of coarser vegetation (similar observations are recorded by Wiebe, 1935).

Growth rate studies on 1,058 shiners from 20 Michigan localities (natural waters) show that, on the average, this species reaches a total length of approximately 3 inches during its second summer, 4 inches during its third summer, 4.5 inches during its fourth, and 5.5 inches during its sixth. In the section of the Huron River below Ann Arbor, enriched by considerable city sewage, the shiner reaches an average length of 3 inches at the end of the first summer of life. Females grow faster, attain a larger size, and live longer than males. A maximum age of eight summers and a maximum total length of approximately ten inches was noted for the species. Maturity is usually reached at a total length of about 2.5 to 3.5 inches; in localities of rapid growth, most fish mature in their second summer, while in localities of slow growth, maturity is usually delayed until the third summer. These data on the growth rate of golden shiners are given more fully in an article to appear in the papers of the Michigan Academy of Sciences. 
Chub sucker - In the Beach ponds this species displayed considerable versatility in the selection of places for egg deposition. The non-adhesive eggs (2 $\mathrm{mm}$. in diameter) were found scattered abundantly over large and small beds of aquatic moss (Amblystegium riparium), among masses of filamentous algae, and among dead grass stubble on submerged pieces of sod. The spawning season at the Beach ponds, somewhat modified by the method of handling the breeders, lasted for about 2 weeks in each pond: the first part of June in one pond, and the latter part of June and the first part of July in the other.

Newly-laid eggs were placed in aerated jars and the 5 to $6 \mathrm{~mm}$. fry hatched in 6 to 7 days under water temperatures ranging from 22.5 degrees to 29.5 degrees $C$.

The number of eggs deposited by one female varies approximately from 3,000 to 20,000, depending upon the size of the female. Both sexes reach maturity in their third summer of life. The chub sucker is a rapidly-growing forage fish, attaining a total length of approximately 3 inches in 1 year, 5 inches in 2 years, 6 inches in 3 years, and 8 inches in 5 years.

Red-bellied dace-This small minnow, occurring in southern Michigan in the extreme southern part of its natural range, is well suited to propagation in cool-water ponds. The eggs are normally, and so far as observed, deposited entirely in masses of filamentous algae. Several times the writer observed a spawning pair or group (one female and several males) dart from one mass of algae to another, performing a short spawning enbrace, of 2 to 4 seconds duration, in each mass. Subsequent examination of each algal mass revealed a few ( 5 to 30 ) non-adhesive eggs scattered through and entangled among the algal filaments. The incubation period was noted as 8 to 10 days. Dissection of females has revealed a simultaneous maturity of several hundred eggs, and the presence of at least two definite size groups of maturing eggs, suggesting that one female spawns at least twice during one season. The spawning season extends from the latter part of May into August. Maturity is reached by many individuals in the second summer of life, and some specimens live at least 3 years.

Menona killifish-In a small pond at the Lydell Hatchery, the eggs of this species were found only in masses of flamentous algae. From eggs ( $2 \mathrm{~nm}$. in diameter) placed in aerated jars, the 6 to $7 \mathrm{~nm}$. fry hatched in 11 to 12 days at water temperatures ranging from 72 degrees $F$. to 80 degrees $F$.

In some localities, both sexes mature first in their third summer of life. The females reach a larger size than the males by the third summer, but there is no sex difference in size at the end of the first summer (Table 3).

\section{Observations on Forage Fishes Eating Bass Fry in Aquaria}

At the suggestion of Dr. Carl L. Hubbs, the writer has conducted several aquarium experiments on the predation by certain species of 
forage fishes on smallmouth bass fry. Sone of the following observations confirm previous reports to this society; others are new.

Under experimental aquarium conditions, adult golden shiners readily ate bass fry $9,10.5$, and 13 to 17 millimeters in length, while fry more than $17 \mathrm{~mm}$. ( $0.75 \mathrm{inch})$ long were either too elusive to be caught or too large to be eaten by the golden shiners. Blunt-nosed minnows readily devoured fry 8 and $10.5 \mathrm{~mm}$. in length, and were able to catch and eat fry up to $15 \mathrm{~mm}$. in length. Red-bellied dace (Chrosomus eos), 2 to 2.5 inches long, ate bass fry 8 to $9 \mathrm{~mm}$. in length. Four to six-inch goldfish readily devoured bass fry 0.5 to 0.75 inch in length. The addition of the blunt-nosed minnow and the redbellied dace (two species with very small mouths) to the list of forage fishes which can eat bass fry suggests that almost all minnows are able to include newly-hatched bass fry in their diet. What the various forage species do eat in natural waters and in hatchery ponds, and not what they are able to catch and devour under experimental aquarium conditions, is, of course, the important issue. Observations at the Northville Hatchery of the U. S. Bureau of Fisheries, where bluntnosed minnows are used in bass-rearing ponds, have failed to indicate that this species consumes bass fry under hatchery pond conditions. Fifteen two- to three-inch minows seined on May 30, 1934, from pond $A$ in which there were many fry as small as $12 \mathrm{~mm}$. in length, and 36 two- to three-inch minnows seined on June 1, 1935, from pond $R$ containing fry 9 to $12 \mathrm{~mm}$. in length, contained no bass fry remains in their stomachs.

\section{Literature Cited}

Hankinson, T. L.

1919. Notes on the Life-histories of Illinois Fish. Trans. Ill. State Acad. of Sci., Vol. 12, pp. 132-150.

1932. Observations on the Breeding Behavior and Habitats of Fishes in Southern Michigan. Pap. Mich. Acad. Sci., Arts, and Letters, Vol. 15,

Hubbs, Carl L. 1931, pp. 411-425.

1934. Some Experiences and Suggestions on Forage Fish Culture. Trans. Am. Fish. Soc., Vol. 63, 1933, pp. 53-63.

Van Cleave, Harley J., and Markus, Henry C.

1929. Studies on the Life History of the Blunt-nosed Minnow. American Naturalist, Vol. 63, pp. 530-539.

Wiebe, A. H.

1935. The Pond Culture of Black Bass. Bull. No. 8, Division of Education and Research, Game, Fish and Oyster Comm., Austin, Texas. 